УДК 539.3

\author{
А.Н. Аношкин ${ }^{1}$, А.Б. Поспелов ${ }^{1}$, Р.М. Якушев ${ }^{2}$ \\ ${ }^{1}$ Пермский национальный исследовательский политехнический \\ университет, Пермь, Россия \\ ${ }^{2}$ Институт технической химии УрО РАН, Пермь, Россия
ОСОБЕННОСТИ ДЕФОРМИРОВАНИЯ И РАЗРУШЕНИЯ КОМБИНИРОВАННЫХ ПОЛИМЕРНЫХ ТРУБ ПРИ НИЗКИХ ТЕМПЕРАТУРАХ

\begin{abstract}
Двухслойные комбинированные конструкции в которых один слой, обладающий высокой прочностью и жестокостью, из металла, армированного композита или высокопрочного пластика является несущим, а другой из высокодеформативного полимера или эластомера обеспечивает герметичность, химическую и коррозионную защиту являются широко распространенными. Однако вследствие различия механических свойств и, в частности, КЛТР в слоях таких конструкций могут возникать значительные напряжения при перепадах температуры. Длительный характер воздействия таких нагрузок, наличие дефектов, сложное напряженное состояние, возникающее в слоях конструкций, а также существенная температурная зависимость физико-механических свойств полимеров, делают вопросы обеспечения длительной механической прочности и работоспособности таких конструкций весьма актуальными. Объектом исследований в настоящей работе являются комбинированные полимерные трубы, состоящие из двух основных слоев: термопласта (полиэтилена низкого давления) и армированного композита (стеклопластика). Целью исследований является выявление причин хрупкого разрушения слоя из термопласта (полиэтилена) при низких температурах. В работе приведены результаты экспериментальных лабораторных исследований образцов полиэтиленового слоя и натурных образцов труб на хладостойкость при температуре до $-50{ }^{\circ} \mathrm{C}$. Проведено сравнение с полученными ранее расчетными оценками технологических остаточных напряжений в данных трубах. Предложена схема испытаний для быстрой сравнительной оценки хрупкости полиэтилена в условиях сложного напряженного состояния при низких температурах. При испытаниях натурных образцов труб выявлены этапы технологического процесса, влияющие на хладостойкость конструкции комбинированных полимерных труб.

Ключевые слова: напряженно-деформированное состояние , разрушение, полиэтилен, стеклопластик, хладостойкость, эксперимент, двухосное нагружение, комбинированные трубы, длительная прочность, технологические напряжения.
\end{abstract}




\author{
A.N. Anoshkin ${ }^{1}$, A.B. Pospelov', R.M. lakushev ${ }^{2}$ \\ ${ }^{1}$ Perm National Research Polytechnic University, Perm, Russian Federation \\ ${ }^{2}$ Institute of Technical Chemistry UrB RAS, Perm, Russian Federation

\section{FEATURES OF LOW-TEMPERATURE DEFORMATION AND FRACTURE OF COMBINED PLASTIC PIPES}

\begin{abstract}
Double-layer composite structures with one load-bearing high-strength layer made of metal, reinforced composite or rigid plastic and other one made of high deformability polymer or elastomer providing high tightness, chemical and corrosion protection are widespread. Due to differences in the mechanical properties and linear thermal expansion coefficient, high level of stresses can occur in the layers of such structures during temperature changes. Considering the long-term nature of loading, the defects probability, the availability of complex stress state in the layers and temperature dependence of the physical and mechanical properties of polymers, the issues of the providing of long-term mechanical strength and failure-free operability of such structures are highly relevant. Object of study in this paper is polymeric pipe combined of two layers made of thermoplastic (HDPE) and fiberglass. The purpose of research is to identify the causes of brittle fracture of thermoplastic layer at low temperatures. The experimental results of cold resistance of HDPE specimens and pipe samples at temperatures down to $50^{\circ} \mathrm{C}$ are presented in this paper. A comparison with the previous results of calculations of technological residual stresses in these pipes was done. The test method for fragility of HDPE under complex stress state at low temperatures was proposed. As a result of pipe samples testing the process steps which can effect on cold resistance of plastic pipes were identified.

Keywords: stress-strain state, fracture, HDPE, polyethylene, fiberglass, cold-resistance, test, bi-axial loading, combined pipe, long-term strength, technological stress.
\end{abstract}

\title{
Введение
}

Комбинированные по толщине конструкции занимают особое место среди изделий из композитных материалов. Такие конструкции, как правило, состоят из двух слоев - армированного слоя и слоя из термопласта или эластомера. Их работоспособность определяется не только свойствами слоев, но и спецификой взаимодействия двух материалов. Аспект взаимодействия особо актуален при рассмотрении работоспособности комбинированных конструкций в условиях низких температур и перепадов температуры. Наиболее типичными комбинированными по радиальному направлению конструкциями являются бипластмассовые трубы. Внутренний слой данных труб из термопласта гарантирует химическую стойкость и герметичность, а конструкционный слой из стеклопластика обеспечивает высокую прочность и жесткость изделия [1-3]. При эксплуатации труб из полимерных материалов, в том числе комбинированных, особое внимание следует обращать на условия, при которых они работают, так как свойства полимерных материалов сильно зависят от многих физико-механических факторов 
$[1,4,5]$. Анализ зарубежного опыта применения бипластмассовых труб [6-10] также показал эффективность их применения вследствие сравнительно простой технологии изготовления и длительного срока службы.

Вопросы механики деформирования трубных полимерных и комбинированных конструкций при низких температурах исследовались в работах Ф.И. Бабенко, Ю.Ю. Федорова [11, 12], А.С. Стручкова [13-16] и др. В работах описываются результаты расчетно-экспериментальных исследований конструкций, процессы их деформирования и разрушения при перепадах температур. Несмотря на это, актуальность темы исследований работоспособности комбинированных конструкций при низких температурах сохраняется в связи с внедрением в районах Западной Сибири и Крайнего Севера сосудов давления, диэлектрических вставок и других изделий из полимерных и комбинированных материалов.

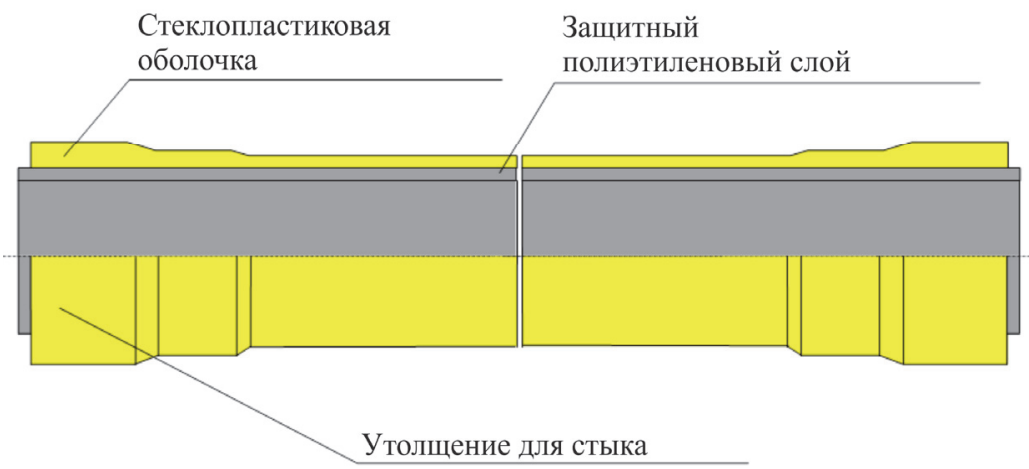

$a$
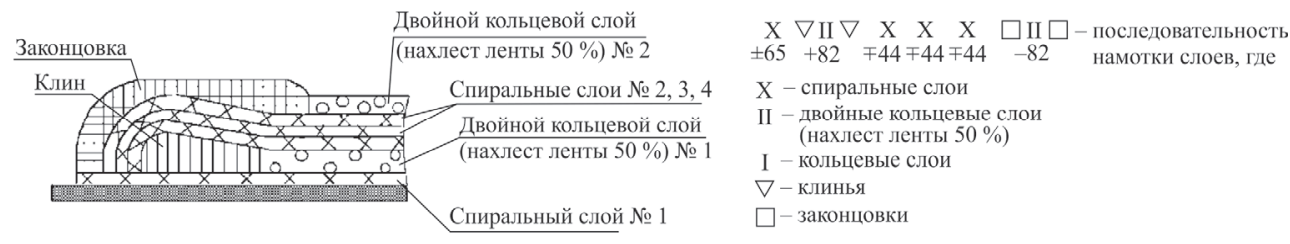

$\sigma$

Рис. 1. Конструкция бипластмассовой трубы $(a)$ и схема армирования стеклопластиковой оболочки (б)

Объектом исследований в настоящей работе являются стеклопластиковые комбинированные (бипластмассовых) трубы, выпускаемые серийно с 1995 г. на нескольких предприятиях Пермского края. Конст- 
рукция бипластмассовых труб, представленная на рис. 1, объединяет в себе два разнородных материала: наружный слой из стеклопластика и внутренний из полиэтилена. Такая конструкция удачно сочетает высокую прочность и жесткость благодаря верхней силовой стеклопластиковой оболочке, а также надежную герметичность вплоть до разрушения вследствие герметичности внутреннего полиэтиленового слоя.

\section{1. Особенности применения комбинированных труб}

Применение комбинированных (бипластмассовых) труб взамен стальных при строительстве и реконструкции промысловых трубопроводов позволяет продлить срок службы последних до 20 лет и более. Бипластмассовые трубы хорошо зарекомендовали себя на нефтепромыслах Уральско-Поволжского региона и начали активно внедряться на нефтепромыслах Западной Сибири в районах с резко континентальным климатом, более длинным зимним периодом и низкими значениями холодных температур [17].

При строительстве опытных участков трубопроводов из бипластмассовых труб в зимний период было зафиксировано несколько случаев выхода конструкции из строя вследствие хрупкого разрушения внутреннего полиэтиленового слоя в виде появления тонких кольцевых трещин (рис. 2). Предварительный осмотр показал, что трещины имеют гладкую поверхность, нехарактерную для поверхностей разрушения полиэтилена, где всегда наблюдаются участки вязкоупругой и пластической деформации - тяжи. Кроме того, ориентация трещин свидетельствует о вероятном появлении их вследствие высоких продольных напряжений до проведения испытаний трубопровода.

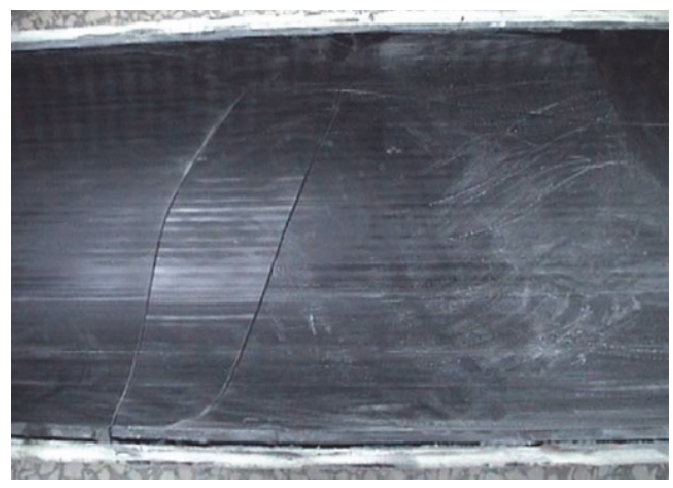

Рис. 2. Хрупкое разрушение полиэтиленовой оболочки в бипластмассовой трубе 
Анализ микрофотографий поверхности сколов и трещин полиэтиленового слоя позволяет сказать, что для большинства образцов характерен смешанный тип разрушения (рис. 3). Наряду с хрупким разрушением, произошедшим по большей части поверхности исследуемого образца, в области, граничащей со стеклопластиковой оболочкой, наблюдается вязкое разрушение. Это свидетельствует о неоднородности поля напряжений либо о неоднородности надмолекулярной структуры по толщине ПЭ слоя.

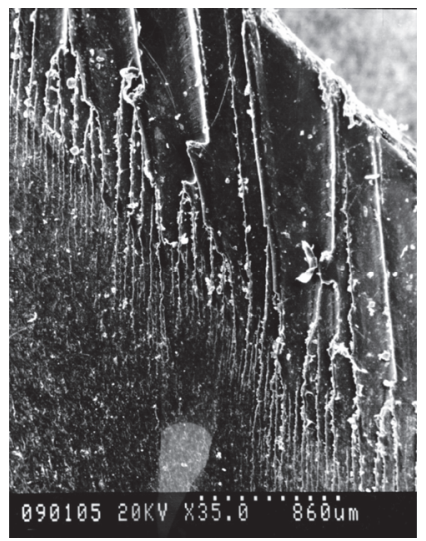

$a$

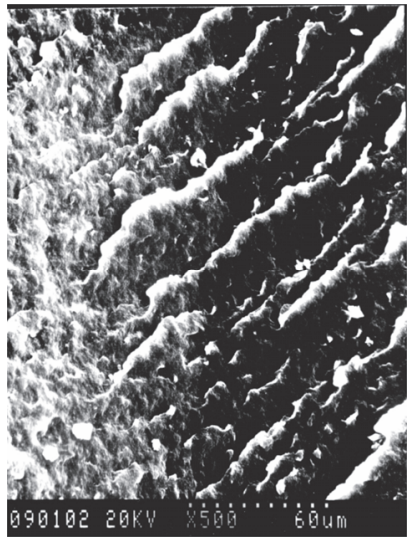

6

Рис. 3. Микрофотографии поверхности трещины на ПЭ слое бипластмассовой трубы (увеличение ×35 (a) и ×500 (б))

Следует отметить, что хрупкое разрушение полиэтиленового слоя наблюдалось приблизительно лишь в 1 \% партии бипластмассовых труб, выпускаемых из одной партии сырья в одинаковых технологических условиях, подверженных приблизительно одинаковым факторам внешних воздействий в процессе хранения, транспортировки и монтажа трубопровода в период с ноября по март. Это показывает, что кроме высоких технологических напряжений и характера напряженного состояния в полиэтиленовом слое существуют еще факторы (или фактор), вызывающие возникновение хрупкой трещины в единичных экземпляpax труб. В качестве гипотезы было принято, что наиболее вероятными факторами, способствующими хрупкому разрушению, являются случайные удары, которым подвергаются трубы при транспортировке и монтаже, и разброс прочностных свойств полиэтилена, который может быть связан с отклонениями или дефектами его надмолекулярной структуры. 
Литературный поиск по работоспособности полимерных и композиционных материалов при низких климатических температурах показал, что для композиционных материалов на основе термореактивного связующего, в частности стеклопластиков, при температурах до $-60^{\circ} \mathrm{C}$ наблюдается сохранение либо повышение модуля упругости [18]. Не было обнаружено и значимое снижение прочностных свойств, а в основном было зафиксировано повышение прочности композитов данного класса. Показателем предела работоспособности полиэтиленовых труб при отрицательных температурах является хрупкое или вязкохрупкое разрушение при ударном нагружении. Температурная граница хрупкого разрушения при ударном воздействии зависит от марки материала и составляет для ПЭ 63 - минус $25^{\circ} \mathrm{C}$, для ПЭ 80 - минус $60^{\circ} \mathrm{C}[19,20]$.

Анализ механизма деформативности труб из полиэтилена ПЭ 80 при низких климатических температурах (до $-44{ }^{\circ} \mathrm{C}$ ) при нагружении внутренним гидростатическим давлением [21] показал, что при температурах ниже $-23,5^{\circ} \mathrm{C}$ наблюдается малая деформируемость материала, характерная для жестких полимеров. Нагружение полиэтилена в этом случае происходило в соотношении осевых напряжений к кольцевым как 1:2, и разрушение происходило со следами пластических деформаций. Испытания труб на внутреннее давление до полного разрушения при температуре ниже минус $40^{\circ} \mathrm{C}$ показывают, что макроскопически разрушение происходит квазихрупко с образованием одиночной трещины, без каких-либо вздутий и пластических деформаций. Фрактограммы показали, что рост трещины начинается с внутренней поверхности трубы, а процесс разрушения происходит весьма сложно и содержит по крайней мере три разные стадии. Доминирующим является вязкопластический вид разрушения.

Интересные результаты получены Ф.И. Бабенко [12] при исследовании на хладостойкость двухслойной конструкции - армированных полимерных труб (АПТ). АПТ состоит из трех слоев: внутреннего и внешнего из полиэтилена и промежуточного - армирующего. Армирование полиэтиленовых труб синтетическими нитями осуществляется либо намоткой заранее подготовленной ленты определенной ширины, состоящей из определенного числа нитей и адгезива (полиэтилен, сэвилен) (тип I производства ЗАО «Сибгазаппара»), либо намоткой отдельных комплексных нитей намоточной машиной без адгезива (тип II производства ООО «Технология композитов»). При исследованиях вы- 
явлена определяющая роль конструктивно-технологического фактора в обеспечении применимости армированных полимерных труб для сооружения трубопроводов в условиях холодного климата. Установлено, что внутренний технологический слой, связывающий армирующие нити и обеспечивающий конструктивную связь между внешним и внутренним полимерными слоями АПТ (тип I), может являться инициатором хрупкого разрушения трубы при температурах ниже минус $15^{\circ} \mathrm{C}$. В трубах с иным конструктивным решением (тип II) наблюдается исключительно вязкий характер разрушения во всем диапазоне климатических температур.

Таким образом, хладостойкость той или иной комбинированной конструкции связана не столько со свойствами применяемых материалов, а с конструктивно-технологическими параметрами самой конструкции, в которой могут возникать высокие напряжения.

Существование высоких напряжений в полиэтиленовом и стеклопластиковом слое бипластмассовых труб при температурном перепаде связано с большим различием (в десять раз) КЛТР данных материалов. Предварительные расчетные исследования [22] показывают, что в полиэтиленовом слое бипластмассовой трубы в процессе хранения, транспортировки и строительства при низких значениях температуры окружающего воздуха возникает объемное напряженно-деформированное состояние. На рис. 4 показано поле НДС образцов труб при температурном перепаде $60{ }^{\circ} \mathrm{C}$ [22]. В работе исследовалось напряженно-деформированное состояние в полиэтиленовом слое трубы в окрестности возможного дефекта - кольцевой зоны нарушения адгезии со стеклопластиком. Как видно из рисунков, в зоне возобновления контакта полиэтилена со стеклопластиком осевые напряжения бZZ достигают $34 \mathrm{MПа,} \mathrm{окружные} \sigma \theta \theta \approx 40$ МПа, без учета технологических напряжений. Такое напряженное состояние является потенциально опасным, поскольку двухосное растяжение в плоскости слоя снижает возможности сдвигового пластического деформирования, делает невозможным упрочнение полимера за счет перестройки его молекулярных цепей, а высокий уровень растягивающих напряжений может привести к разрушению при отсутствии пластической деформации и длительном времени воздействия нагрузки. Однако в литературе отсутствует критерий длительной прочности для оценки хрупкого разрушения полиэтилена при двухосном напряженном состоянии при низких температурах. 

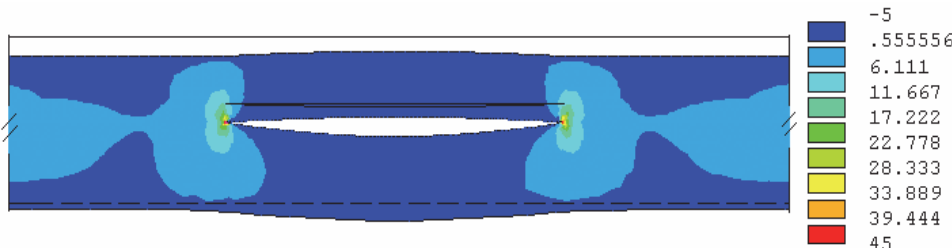

SX, MПа

45

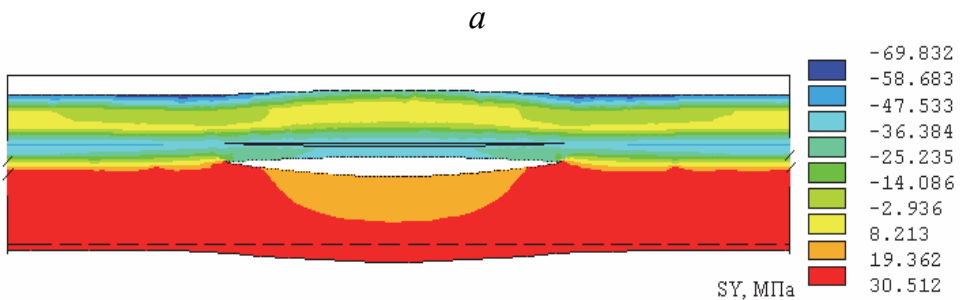

6

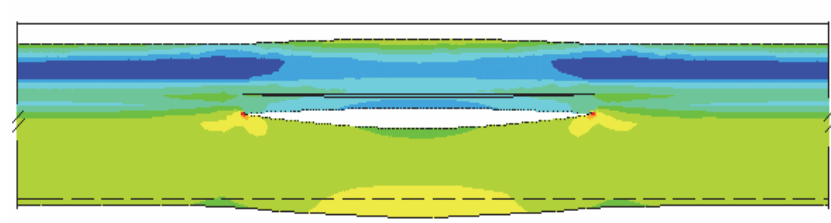

$-20.274$

$-12.589$

$-4.904$

2. 782

10.467

18.153

25.838

33.523

41.209

SZ, MПа

48.894

B

Рис. 4. Поля напряжений $\sigma \mathrm{rr}(a), \sigma \theta \theta(б), \sigma \mathrm{zz}($ ( ) в зоне локального отслоения полиэтиленового слоя от стеклопластиковой оболочки бипластмассовой трубы $D=130$ мм при температурном перепаде от +20 до $-40{ }^{\circ} \mathrm{C}$

Из литературных источников $[23,24]$ известно, что материал полиэтиленовых труб (полиэтилен низкого давления) обладает существенной деформационной способностью при длительном одноосном нагружении в квазиравновесных условиях, включая область отрицательных температур (вплоть до $-80^{\circ} \mathrm{C}$ ). Хрупкое разрушение полиэтиленового слоя бипластмассовых труб обусловлено, по-видимому, сложным напряженно-деформированным состоянием и одновременно высоким уровнем напряжений, возникающих на границе полиэтилен - стеклопластик при температурном перепаде. В литературе известны схемы нагружения и экспериментальные установки для испытания материалов при сложном нагружении $[24,25]$. В большинстве случаев для проведения таких испытаний требуется весьма сложное оборудование. При этом оборудование еще более усложняется в случае необходимости проведения испытаний полимеров, обладающих значительно большей деформационной способностью, нежели металлы, а также при 
испытаниях в условиях нагрева и особенно охлаждения. В последнем случае объем термокриокамеры часто является недостаточным для размещения в ней испытываемого образца вместе с оснасткой.

\section{2. Испытания образцов труб на двухосное нагружение}

Для подтверждения возможности моделирования хрупкого разрушения полиэтиленовой оболочки бипластмассовых труб в лабораторных условиях был проведен ряд экспериментов на натурных образцах труб. Для качественной оценки прочности полиэтиленового слоя в условиях двухосного растяжения вследствие температурного перепада была предложена схема испытаний, рассмотренная ниже. На рис. 5 показано приспособление, представляющее собой два металлических плоских кольца (толщиной не менее 3 мм) с рифленой поверхностью и четырьмя отверстиями под болты. Образец ПЭ трубы распиливается вдоль образующей, распрямляется (на рисунке серый прямоугольник), фиксируется струбцинами между кольцами и нагревается в воздушном термостате в течение 3-4 часов. Затем в ПЭ образце высверливаются отверстия, и нагретый образец ПЭ фиксируется болтами.

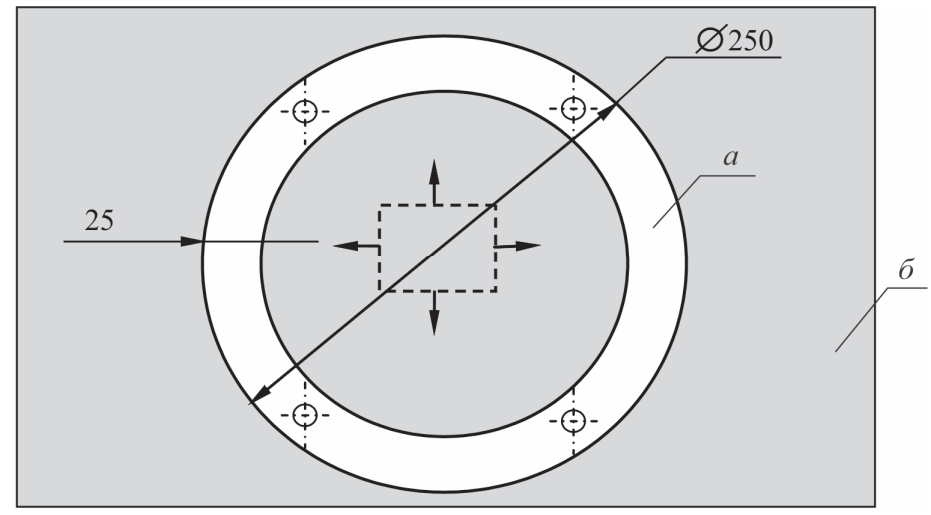

Рис. 5. Приспособление ( $a$ ) и образец (б) для испытаний на двухосное растяжение

Далее образец охлаждается до заданной температуры на воздухе либо в криокамере. При этом вследствие существенного отличия КЛТР полиэтилена и металлических колец в образце возникают растягивающие напряжения. В центре образца (прямоугольник, обозначенный пунктирной линией на рис. 5) напряженное состояние является близким к двухосному. Подбирая температурные режимы закрепления 
и охлаждения, в образце можно получить напряженное состояние, близкое к тому, которое возникает в полиэтиленовом слое бипластмассовой конструкции при охлаждении в случае хорошей адгезии полиэтилена к стеклопластику. Примечательно, что зафиксированный в данном приспособлении образец может подвергаться дополнительному нагружению в поперечной плоскости, выдерживать заданное время для проведения испытаний на длительную прочность, а также подвергаться комбинации данных нагрузок.

С целью оценки работоспособности предлагаемой методики были проведены следующие испытания.

1. Плоский образец вырезался из полиэтиленовой трубы $\varnothing 190$ мм, закреплялся в нагретом состоянии $\left(\approx+60^{\circ} \mathrm{C}\right)$ в испытательной оснастке и охлаждался до температуры порядка $\approx-60{ }^{\circ} \mathrm{C}$. Затем образец подвергался многократному ударному воздействию на механическом копре (масса груза 5 кг, высота 100 мм, индентор - конус с радиусом основания 10 мм и углом при вершине 60). В результате четвертого удара наблюдалось хрупкое разрушение с развитием трещины из точки контакта индентора с образцом к периферии образца (рис. 6, a). Трещина имеет гладкую поверхность, идентичную наблюдаемой, в случае хрупкого разрушения полиэтиленового слоя бипластмассовых труб.

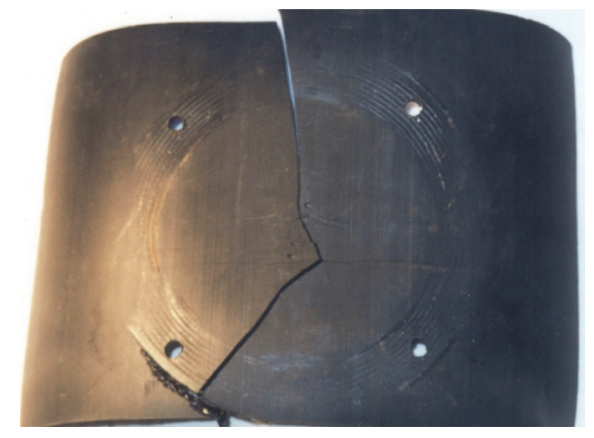

$a$

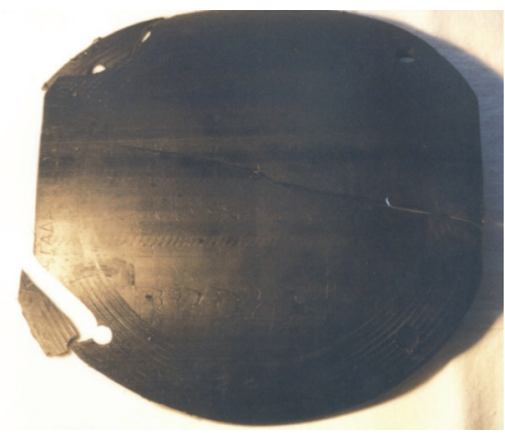

$\sigma$

Рис. 6. Хрупкое разрушение образцов из полиэтиленовых труб $\varnothing 190$ мм ( $a$ ) и $\varnothing 130$ мм (б) при двухосном нагружении и ударе; температура испытаний $-60{ }^{\circ} \mathrm{C}$

Приближенная оценка напряжений полиэтиленового образца [26] при температурном перепаде $120^{\circ} \mathrm{C}$, проведенная по соотношению, показала, что в образце реализуются температурные напряжения порядка 42 МПа без учета ударных воздействий. 


$$
\sigma_{z}=\sigma_{\theta}=\frac{\left(\alpha_{p}-\alpha_{s}\right) E \cdot \Delta t}{1-v}
$$

где $\sigma_{z}, \sigma_{\theta}$ - соответственно осевое и окружное напряжение; $E$ - модуль упругости полиэтилена, $E=2275$ МПа; $v$ - коэффициент Пуансона, $v=0,3 ; \alpha_{p}-$ коэффициент линейного температурного расширения полиэтилена, $\alpha_{p}=12 \cdot 10^{-5} ; \alpha_{s}-$ коэффициент линейного температурного расширения стали, $\alpha_{s}=12 \cdot 10^{-6} ; \Delta t-$ перепад температур, $\Delta t=120^{\circ} \mathrm{C}$.

2. Плоский образец вырезался из полиэтиленовой трубы $\varnothing 130$ мм, закреплялся в нагретом состоянии $\left(\approx+60{ }^{\circ} \mathrm{C}\right)$. Далее образец выдерживался в морозильной камере в течение 5 суток при температуре $-25 \ldots-28^{\circ} \mathrm{C}$, периодически (раз в сутки) подвергался ударному воздействию, при этом разрушения образца не зафиксировано. После этого образец охлаждался в криокамере до температуры порядка $\approx-60{ }^{\circ} \mathrm{C}$ и затем подвергался нескольким ударам по вышеописанной схеме. В результате третьего удара получено хрупкое разрушение, аналогичное предыдущему испытанию (рис. 6, б).

Кроме того, при извлечении образца из приспособления обнаружено хрупкое разрушение в местах крепления двух болтов (см. рис. 6, б). Данное разрушение могло произойти раньше ударного нагружения и привести к частичной разгрузке образца.

Таким образом, используя предложенную схему испытаний, получили хрупкое разрушение образцов из полиэтиленовых труб, аналогичное наблюдаемому в полиэтиленовом слое бипластмассовых труб в натурных условиях при уровнях напряжений порядка 46 МПа. Причиной разрушения является сочетание следующих факторов: высокий уровень напряжений, сложное напряженно-деформированное состояние, осложненное, повидимому, стеклованием аморфной фазы полиэтилена, что в сумме повышает его хрупкость. Разрушение может быть спровоцировано дополнительными ударными нагружениями и микродефектами.

На основе предложенной схемы испытаний можно разработать экспресс-метод для быстрой сравнительной оценки хрупкости полиэтилена в условиях сложного напряженного состояния при низких температурах. Использование данного метода предполагается проводить в комплексе с работами по модификации рецептуры полиэтилена с целью снижения его температуры стеклования, повышения пластичности и вязкости разрушения при низких температурах. 


\section{3. Испытания натурных образцов труб на хладостойкость}

С целью исследования хладостойкости натурных образцов бипласмассовых труб при температурном перепаде был проведен комплекс испытаний образцов труб. Образцы изготавливались с вариациями конструкторских и технологических параметров. Предполагалось, что на хладостойкость конструкции влияют марка и свойства полиэтилена, из которого изготовлена внутренняя герметизирующая оболочка и ее напряженно-деформированное состояние в составе бипластмассовой трубы. В свою очередь, на напряженно-деформированное состояние полиэтиленовой оболочки влияют наличие адгезионной связи между оболочками и технологические напряжения, заложенные на этапах:

- экструдирования полиэтиленовой трубы;

- намотки стеклопластиковой оболочки;

- полимеризации стеклопластикового слоя;

- охлаждения.

Испытаниям подвергались натурные образцы труб, изготовленные с варьированием следующих конструктивных и технологических параметров:

- для изготовления полиэтиленовой оболочки использовался полиэтилен низкого давления марок 273-79 (ПЭ63) и F3802В (ПЭ80);

- при изготовлении ряда образцов бипластмассовых труб применялись оправки с разными профилями рабочей поверхности - одна с большой непрямолинейностью, а вторая с более гладкой формой поверхности;

- использовалась различная максимальная температура термообработки труб: $106-109$ и $117-119{ }^{\circ} \mathrm{C}$;

- ряд образцов изготавливались с адгезионной связью между полиэтиленом и стеклопластиком, имеющей локальные зоны непроклея, или при полном отсутствии связи;

- в образцах создавалось начальное напряженно-деформированное состояние в осевом направлении. Для этой цели производилась фиксация полиэтиленовой оболочки в стеклопластиковой по краям образцов при повышенной температуре (адгезионная связь по всей поверхности отсутствовала). Температура выбиралась таким образом, чтобы обеспечить относительную деформацию полиэтилена, равную $3 \%$ при температуре $20^{\circ} \mathrm{C}$. 
Соответствие между группами образцов и использованными конструктивными и технологическими параметрами приведено в табл. 1 .

При этом в каждой группе образцы труб отличались между собой только одним параметром при неизменных остальных. Таким образом, при испытаниях планировалось выявить влияние какого-либо параметра на хладостойкость бипластмассовых труб.

Таблица 1

Группы исследуемых образцов труб

\begin{tabular}{|c|c|c|c|}
\hline \begin{tabular}{|c|} 
Номера \\
группы \\
и образца \\
\end{tabular} & $\begin{array}{l}\text { Наименование технологического } \\
\text { или конструктивного параметра }\end{array}$ & Значение параметра & Примечание \\
\hline $1-1$ & \multirow{2}{*}{ Профиль оправки } & $\begin{array}{l}\text { № } 1 \text { с гладкой } \\
\text { поверхностью }\end{array}$ & \\
\hline $1-2$ & & $\begin{array}{c}\text { № } 2 \text { с отклонениями } \\
\text { профиля }\end{array}$ & \\
\hline $2-1$ & \multirow{2}{*}{$\begin{array}{l}\text { Максимальная температура } \\
\text { термообработки (полимериза- } \\
\text { ции) труб }\end{array}$} & $106-109^{\circ} \mathrm{C}$ & \multirow{2}{*}{$\begin{array}{c}\text { Образцы } \\
\text { с ПЭ марки } \\
\text { F3802B }\end{array}$} \\
\hline $2-2$ & & $117-119^{\circ} \mathrm{C}$ & \\
\hline $3-1$ & \multirow{4}{*}{$\begin{array}{l}\text { Наличие адгезионной связи } \\
\text { полиэтилен-стеклопластик }\end{array}$} & $\begin{array}{c}\text { Кольцевой непроклей } \\
\text { шириной } 50 \text { мм }\end{array}$ & \\
\hline $3-2$ & & $\begin{array}{c}\text { Кольцевой непроклей } \\
\text { шириной } 200 \text { мм }\end{array}$ & \\
\hline $3-3$ & & $\begin{array}{c}\text { Осевой непроклей } \\
\text { с размерами } 150 \times 1000 \text { мм } \\
\end{array}$ & \\
\hline $3-4$ & & Без адгезионной связи & \\
\hline $4-1$ & \multirow{2}{*}{$\begin{array}{l}\text { Наличие начальной осевой } \\
\text { деформации }\end{array}$} & $\varepsilon=0 \%$ & \multirow{2}{*}{$\begin{array}{c}\text { Образцы без } \\
\text { адгезионной } \\
\text { связи }\end{array}$} \\
\hline $4-2$ & & $\varepsilon=3 \%$ & \\
\hline
\end{tabular}

Испытания проводились в климатической камере КК-1 лаборатории физико-механических свойств ИМСС УрОРАН с охлаждающей системой Ditzer Kuhlmaschinenbau (Германия) и максимальной температурой охлаждения до $-50^{\circ} \mathrm{C}$.

Образцы представляли собой отрезки труб внутренним диаметром 190 мм и длиной 1,5 м. Для обеспечения совместной работы в осевом направлении полиэтиленовая оболочка образцов была скреплена со стеклопластиковой оболочкой с каждой стороны болтами М5х25 в 2 ряда по 8 болтов в каждом ряду, расстояние между рядами $\approx 50$ мм. Болты в рядах сдвинуты относительно друг друга в шахматном порядке.

Для имитации внешнего воздействия на трубы, возникающего в процессе погрузки и транспортировки, образцы труб подвергались ло- 
кальным ударным нагрузкам в виде падения образцов из вертикального положения в горизонтальное, а также падение на них груза весом 5 кг с высоты 1 м от верхней образующей трубы для имитации засыпки труб неразмягченным грунтом в процессе строительно-монтажных работ.

Методика испытаний образцов заключалась в циклическом воздействии на образцы в следующем порядке:

- помещение образцов в климатическую камеру при температуре испытаний;

- выдержка при этой температуре в течение суток;

- осмотр образцов на появление растрескивания полиэтилена;

- имитация удара в виде падения образцов;

- осмотр образцов;

- имитация удара в виде падение на них груза;

- осмотр образцов.

Данное циклическое воздействие проводилось при температуре в камере $-10,-20,-30,-40$ и $-50{ }^{\circ} \mathrm{C}$. Далее образцы вновь подвергались циклическим воздействиям при температурах -40 и $-50{ }^{\circ} \mathrm{C}$ с выдержкой образцов между циклами испытаний в течение суток при комнатной температуре.

Результаты испытаний образцов бипластмассовых труб на хладостойкость приведены в табл. 2.

Таблица 2

Результаты испытаний образцов бипластмассовых труб на хладостойкость

\begin{tabular}{|c|c|c|c|c|}
\hline $\begin{array}{c}\text { Номера } \\
\text { группы и } \\
\text { образца }\end{array}$ & $\begin{array}{c}\text { Количество } \\
\text { образцов }\end{array}$ & $\begin{array}{c}\text { Т разру- } \\
\text { шения, }{ }^{\circ} \mathrm{C}\end{array}$ & $\begin{array}{c}\text { Приме- } \\
\text { чание }\end{array}$ \\
\hline $1-1$ & 2 & & Не разрушился & \\
\hline $1-2$ & 2 & & Не разрушился & \\
\hline $2-1$ & 1 & & Не разрушился & \\
\hline $2-2$ & 1 & -50 & $\begin{array}{c}\text { Спиральные и кольцевые трещины } \\
\text { по всей длине }\end{array}$ & Рис. 7 \\
\hline $3-1$ & 1 & & Не разрушился & \\
\hline $3-2$ & 1 & & Не разрушился & \\
\hline $3-3$ & 1 & & Не разрушился & \\
\hline $3-4$ & 1 & & Не разрушился & \\
\hline $4-1$ & 1 & & Не разрушился & \\
\hline $4-2$ & 1 & -40 & $\begin{array}{c}\text { Без удара. Кольцевая трещина на } \\
\text { 2/3 окружности в районе отбортов- } \\
\text { ки с одного торца }\end{array}$ & \\
\hline
\end{tabular}


Анализируя результаты испытаний образцов бипластмассовых труб на хладостойкость, можно сделать вывод, что хрупкое разрушение происходит в трубах, которые подвергались термообработке при повышенных температурах (образец 2-2), а также имеющих начальное напряженно-деформированное состояние (образец 4-2). Фотография разрушенного образца трубы представлена на рис. 7.

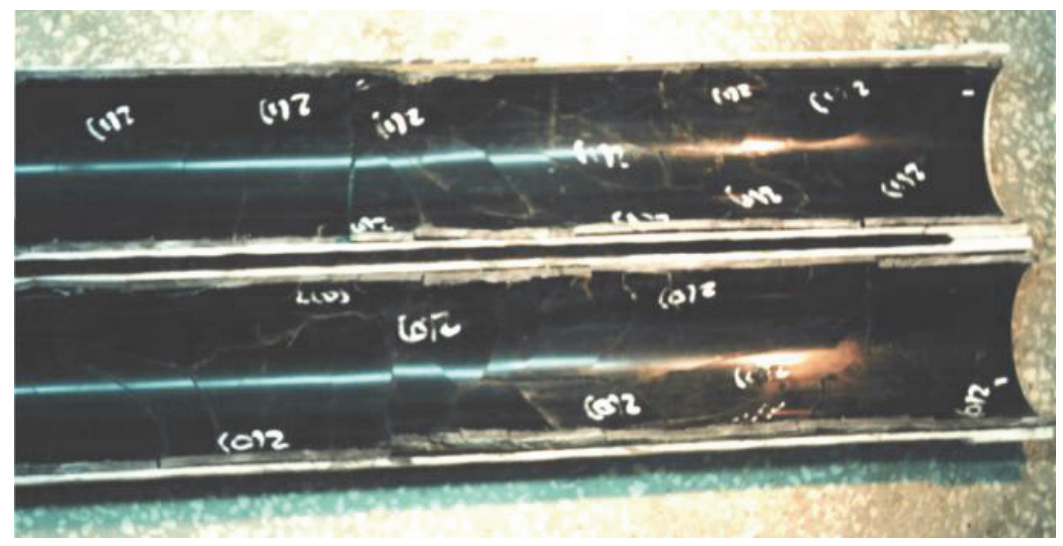

Рис. 7. Разрушение полиэтиленового слоя образца 2-2 трубы ТСК190 (максимальная температура полимеризации $118^{\circ} \mathrm{C}$ )

Случай разрушения полиэтиленовой оболочки бипластмассовой трубы, прошедшей термообработку при повышенной температуре, объясняется тем, что повышенная температура термообработки трубы вызывает более высокие технологические напряжения, которые возникают в полиэтиленовой оболочке на данном этапе, что подтверждается расчетами напряженно-деформированного состояния [27, 28].

Во втором случае начальная осевая деформация полиэтиленовой оболочки привела к возникновению в ней начальных напряжений порядка 33 МПа, что соизмеримо с уровнем технологических напряжений $[27,28]$. Охлаждение образца до температуры $-40{ }^{\circ} \mathrm{C}$ приводит к возникновению растягивающих напряжений в полиэтиленовом слое до уровня 50 МПа.

Таким образом, результаты испытаний конструкции бипластмассовых труб на хладостойкость подтверждают предыдущие выводы о том, что уровень напряжений в полиэтиленовом слое порядка 50 МПа является потенциально опасным с точки зрения хрупкого разрушения. 


\section{Выводы}

Подводя итоги оценки особенностей деформирования комбинированных бипластмассовых труб при низких температурах, можно сделать следующие выводы.

1. Вследствие совместной работы материалов с различными физико-механическими свойствами в составе конструкции в слоях последней возникают эксплуатационные напряжения, приводящие в ряде случаев к возникновению эффектов, которые не проявляются в случае раздельной работы материалов, входящих в состав конструкции. В бипластмассовых трубах этот эффект проявляется в виде хрупкого разрушения полиэтиленового слоя.

2. Хрупкое разрушение полиэтиленового слоя в бипластмассовых трубах вызвано объемным напряженно-деформированным состоянием в слое с учетом технологических и эксплуатационных (температурных) напряжений. Двухосное растяжение в плоскости слоя снижает возможности сдвигового пластического деформирования полимера и делает невозможным его упрочнение за счет перестройки молекулярных цепей, при этом высокие растягивающие напряжения могут привести к разрушению полимера при отсутствии пластической деформации и длительном времени воздействия нагрузки. Испытания образцов полиэтилена на одноосное растяжение не дают представления о механизмах и не позволяют получить критериальные оценки хрупкого разрушения полиэтиленового слоя.

3. В процессе исследований разработана и опробована схема испытаний полиэтиленового слоя, имитирующая двухосное нагружение. Использование данной схемы возможно для быстрой сравнительной оценки хрупкости полиэтилена в условиях сложного напряженного состояния при низких температурах.

4. Испытания натурных образцов бипластмассовых труб на хладостойкость подтверждают наличие в полиэтиленовой оболочке эксплуатационных и технологических напряжений, обусловливающих хрупкое разрушение полиэтиленового слоя при длительном нагружении и дополнительных ударных нагрузках. По результатам испытаний и сопоставления с результатами предыдущих расчетов можно сделать вывод, что критическое значение потенциально опасных двухосных растягивающих напряжений в полиэтиленовом слое составляет порядка 50 МПа. 
5. Для более точной оценки работоспособности и хладостойкости комбинированных полимерных конструкций требуется проведение более детальных исследований особенностей механического поведения полимерных материалов при кратковременном и длительном двухосном нагружении в условиях низких температур и ударных воздействий.

\section{Библиографический список}

1. Рябец Ю.С, Булманис В.Н., Давыдова Н.Н. Разработка конструкции и технологии хладостойких бипластмассовых труб // Экспрессинформация НИИТЭХИМ. Эксплуатация, ремонт, защита от коррозии оборудования и сооружений. Вып. 4. - М., 1988. - С. 1-12.

2. Ларионов А.Ф. Материалы и технология бипластмассовых труб, узлов стыка и соединительных элементов внутрипромысловых нефтепроводов: дис. ... канд. техн. наук. - Пермь, 2000. - 156 с.

3. Создание трубопроводных систем с применением бипластмассовых и полимерных композиционных материалов для изделий гражданской морской техники / О.С. Сироткин [и др.] // Молодой ученый. 2013. - № 5. - С. 101-104.

4. Павлов Н.Н. Старение пластмасс в естественных и искусственных условиях. - М.: Химия, 1982. - 224 с.

5. Булманис В.Н. Эксплуатационная устойчивость полимерных волокнистых композитов и изделий в условиях холодного климата: дис. ... д-ра техн. наук; Институт физико-технических проблем Севера СО АН СССР. - Якутск, 1989. - 472 с.

6. Haddad G.N. Recent Innovations in PVC/FXP Composite Pipe. Polym. // Plast. Techn. Eng. - 1977. - 9/2. - P. 207-25L

7. Usemann K.W. Kunststofferohre in der Trinkwasserinstallaion // Neue DELIWA-Z. - 1987. - Bd. 38. - No. I. - P. 5-8.

8. White R.J., Phillips R.G. Environmental Stress-Rupture Mechanisms in Glass Fibre/Polyester Laminates // Proceedings of 5th Intern.Conf. on Compos. Mater. (ICCM-5). - San Diego; California, 1985. - P. 1089-1099.

9. Cowley W.E., Deut N.P., Morris R.H. The Brittle Failure of UPVC Lined Glass Reinforced Plastics Pipe Lines // Chemistry and Industry. 1978. - No. 6. - P. 365-369.

10. Guan Z.W., Boot J.C. Creep analysis of polymeric pipes under internal pressure // PolymEngSci, 2001. - Vol. 41. - No. 6. - P. 955-961. 
11. Бабенко Ф.И., Федоров Ю.Ю. Оценка несущей способности армированных полиэтиленовых труб для газопроводов в условиях холодного климата // Наука и образование. - 2009. - № 1. - С. 46-49.

12. Бабенко Ф.И., Федоров Ю.Ю. Деформационно-прочностные свойства армированных полиэтиленовых труб российского производства при низких температурах [Электронный ресурс] // Нефтегазовое дело: электрон. науч. журн. - 2010. - № 2. - С. 69. - URL: http://www.ogbus.ru/autors/Babenko1.pdf (дата обращения: 28.05.2014).

13. Стручков А.С. Расчет внутренних сдвиговых усилий в бипластмассовой трубе в области конструктивного соединения при отрицательных температурах // Физико-технические проблемы Севера (ч. III): тр. междунар. конф. - Якутск: Изд-во Якут. науч. центра СО РАН, 2000. - C. 32-43.

14. Стручков А.С., Колодезников И.Н. Осевые температурные напряжения в полиэтиленовом трубопроводе из ПЭ80 при воздействии низких температур // EURASTRENCOLD-2002: тр. I Евразийского симпозиума (ч. II). - Якутск: Изд-во Якут. науч. центра СО РАН, 2002. C. $175-181$.

15. Стручков А.С, Родионов А.К., Лапий Г.П. Хладостойкость бипластмассовых труб, предназначенных для транспортировки нефти // Химия нефти и газа: материалы V Междунар. конф. - Томск: Изд-во Ин-та оптики атмосферы СО РАН, 2003. - С. 294-296.

16. Стручков А.С., Федоров С.П., Колодезников И.Н. Температурные напряжения в газовых полиэтиленовых трубах при низких климатических температурах // Химия нефти и газа: материалы V Междунар. конф. - Томск: Изд-во Ин-та оптики атмосферы СО РАН, 2003. C. 296-299.

17. Поспелов А.Б., Тараканов А.И., Шаклеин О.В. Опыт применения стеклопластиковых комбинированных (бипластмассовых) труб при обустройстве нефтяных месторождений // Трубопроводы и экология. - 2003. - № 3 - С. 24-25.

18. Бабенко Ф.И., Булманис В.Н., Родионов А.К. Инженерная климатология полимерных материалов // Физико-технические проблемы Севера (ч. II): тр. междунар. конф. - Якутск: Изд-во Якут. науч. центра СО РАН, 2000. - С. 62-81.

19. Температурные ограничения на условия транспортировки труб и монтажа полиэтиленовых трубопроводов / Ф.И. Бабенко, В.И. Ива- 
нов, Н.А. Коваленко, А.К. Родионов // EURASTRENCOLD-2002: труды I Евразийского симпозиума (ч. IV). - Якутск: Изд-во Якут. науч. центра CO PAH, 2002. - C. 3-9.

20. Рябец Ю.С., Булманис В.Н. Прочность и деформативность полимерных труб при эксплуатации в условиях холодного климата // Известия СО АН СССР. Серия технических наук. - Новосибирск: Наука, 1989. - Вып. 1. - С. 106-109.

21. Стручков А.С. Хладостойкость и особенности сопротивления разрушению нефтегазовых пластмассовых труб: дис. ... д-ра техн. наук; Институт неметаллических материалов СО РАН. - Якутск, 2005. - 398 с.

22. Аношкин А.Н., Поспелов А.Б. Оценка прочности композитных бипластмассовых труб при их эксплуатации в условиях низких температур // Нефтяное хозяйство. - 2008 - № 9. - С. 56-58.

23. Бокшицкий М.Н. Длительная прочность полимеров. - М.: Химия, 1978. - 308 с.

24. Гольдман А.Я. Прогнозирование деформационно-прочностных свойств полимерных и композиционных материалов. - Л.: Химия, 1988. -272 c.

25. Испытательная техника: справочник: в 2 кн. / под ред. В.В. Клюева. - М.: Машиностроение, 1982. - Кн. 2. - 560 с.

26. Чижевский К.Г. Расчет круглых и кольцевых пластин: справ. пособие. - Л.: Машиностроение, 1977. - 184 с.

27. Расчет технологических напряжений в процессе производства бипластмассовых труб / А.Н. Аношкин, А.А. Ташкинов, А.Ф. Ларионов, А.Б. Поспелов // Вестник ПГТУ. Полимерные материалы; Перм. гос. техн. ун-т. - Пермь, 1997 - № 3. - С. 24-32.

28. Исследование механических свойств и оценка напряженного состояния полиэтиленового слоя бипластмассовых труб при низких температурах / А.Н. Аношкин, А.Ф. Ларионов, А.Б. Поспелов, Р.М. Якушев // Вестник ПГТУ. Аэрокосмическая техника; Перм. гос. техн. ун-т. Пермь, 2004 - № 16. - С. 5-11.

\section{References}

1. Riabets Iu.S, Bulmanis V.N., Davydova N.N. Razrabotka konstruktsii i tekhnologii khladostoikikh biplastmassovykh trub [Development of design and technology of cold-resistant biplastic pipes]. Ekspressinformatsiia Nauchno-issledovatel'skogo instituta tekhniko-ekonomicheskikh issledovanii. Seriia "Ekspluatatsiia, remont, zashchita ot korrozii oborudovaniia i sooruzhenii", vol. 4. Moscow, 1988, pp. 1-12. 
2. Larionov A.F. Materialy i tekhnologiia biplastmassovykh trub, uzlov styka i soedinitel'nykh elementov vnutripromyslovykh nefteprovodov [Materials and technology biplastic pipes joint nodes and connecting elements infield pipelines]. Thesis for the degree of candidate of technical sciences. Permskii gosudarstvennyi tekhnicheskii universitet, 2000, $156 \mathrm{p}$.

3. Sirotkin O.S. [et al.] Sozdanie truboprovodnykh sistem s primeneniem biplastmassovykh i polimernykh kompozitsionnykh materialov dlia izdelii grazhdanskoi morskoi tekhniki [Creation of pipeline systems using biplastic and polymer composite materials for civil marine engineering products]. Molodoi uchenyi, 2013, no. 5, pp. 101-104.

4. Pavlov N.N. Starenie plastmass v estestvennykh i iskusstvennykh usloviiakh [Aging of plastics in natural and artificial conditions]. Moscow: Khimiia, 1982. 224 p.

5. Bulmanis V.N. Ekspluatatsionnaia ustoichivost' polimernykh voloknistykh kompozitov i izdelii $\mathrm{v}$ usloviiakh kholodnogo klimata [Operational stability of polymer fiber composites and products in a cold climate]. Thesis of doctor's degree dissertation. Iakutsk, Institut fiziko-tekhnicheskikh problem Severa Akademii Nauk SSSR,1989. 472 p.

6. Haddad G.N. Recent Innovations in PVC/FXP Composite Pipe. Polym. Plast. Techn. Eng., 1977, vol. 9-2, pp. 207-251

7. Usemann K.W. Kunststofferohre in der Trinkwasserinstallaion. Neue DELIWA-Z, 1987, bd. 38, no. 1, pp. 5-8.

8. White R.J., Phillips R.G. Environmental Stress-Rupture Mechanisms in Glass Fibre. Polyester Laminates, Proceedings of 5th Intern.Conf. on Compos. Mater. (ICCM-5). San Diego, California, 1985, pp. 1089-1099.

9. Cowley W.E., Deut N.P., Morris R.H. The Brittle Failure of UPVC Lined Glass Reinforced Plastics Pipe Lines. Chemistry and Industry, 1978, no. 6 , pp. 365-369.

10. Guan Z.W., Boot J.C. Creep analysis of polymeric pipes under internal pressure. PolymEngSci., 2001, vol. 41, no. 6, pp. 955-961.

11. Babenko F.I., Fedorov Iu.Iu. Otsenka nesushchei sposobnosti armirovannykh polietilenovykh trub dliagazoprovodov $\mathrm{v}$ usloviiakh kholodnogo klimata [Evaluation of bearing capacity of reinforced polyethylene pipes for gas pipelines in cold climates]. Nauka i obrazovanie, 2009, no. 1, pp. 46-49. 
12. Babenko F.I., Fedorov Iu.Iu. Deformatsionno-prochnostnye svoistva armirovannykh polietilenovykh trub rossiiskogo proizvodstva pri nizkikh temperaturakh [The stress-strain properties of reinforced polyethylene pipes of Russian production at low temperatures]. Elektronnyi nauchnyi zhurnal Neftegazovoe delo, 2010, no. 2, p. 69, available at: http://www.ogbus.ru/autors/Babenko1.pdf.

13. Struchkov A.S. Raschet vnutrennikh sdvigovykh usilii v biplastmassovoi trube $\mathrm{v}$ oblasti konstruktivnogo soedineniia pri otritsatel'nykh temperaturakh [Calculation of internal shear in biplastmassovoy pipe in constructive connections at low temperatures]. Trudy mezhdunarodnoi konferentsii "Fiziko-tekhnicheskie problemy Severa (chast' III)". Iakutskii nauchnyi tsentr Rossiiskoi akademii nauk, 2000, pp. 32-43.

14. Struchkov A.S., Kolodeznikov I.N. Osevye temperaturnye napriazheniia $\mathrm{v}$ poli-etilenovom truboprovode iz PE80 pri vozdeistvii nizkikh temperature [Axial thermal stresses in a plastic pipe of PE80 at lower temperatures]. Trudy I Evraziiskogo simpoziuma "EURASTRENCOLD-2002" (chast' II). Iakutskii nauchnyi tsentr Rossiiskoi akademii nauk, 2002, pp. 175-181.

15. Struchkov A.S., Rodionov A.K., Lapii G.P. Khladostoikost' biplastmassovykh trub, prednaznachennykh dlya transportirovki nefti [Cold resistance biplastmassovyh pipes for transporting oil]. Materialy V mezhdunarodnoi konferentsii "Khimiia nefti i gaza". Institut optiki atmosfery Sibirskogo otdeleniia Rossiiskoi akademii nauk, Tomsk, 2003, pp. 294-296.

16. Struchkov A.S., Fedorov SP., Kolodeznikov I.N. Temperaturnye napriazheniia $\mathrm{V}$ gazovykh polietilenovykh trubakh pri nizkikh klimaticheskikh temperaturakh [Thermal stresses in gas polyethylene pipes at low climatic temperatures]. Materialy $V$ mezhdunarodnoi konferentsii "Khimiia nefti i gaza". Institut optiki atmosfery Sibirskogo otdeleniia Rossiiskoi akademii nauk. Tomsk, 2003, pp. 296-299.

17. Pospelov A.B., Tarakanov A.I., Shaklein O.V. Opyt primeneniya stekloplastikovykh kombinirovannykh (biplastmassovykh) trub pri obustroistve neftianykh mestorozhdenii [Experience of using fiberglass composite (biplastic) pipes in development of oil fields]. Truboprovody $i$ ekologiia, 2003, no. 3, pp. 24-25.

18. Babenko F.I., Bulmanis V.N., Rodionov A.K. Inzhenernaia klimatologiya polimernykh materialov [Engineering plastics climatology]. Trudy mezhdunarodnoi konferentsii "Fiziko-tekhnicheskie prob- 
lemy Severa (chast' II)". Iakutskii nauchnyi tsentr Rossiiskoi akademii nauk, 2000, pp. 62-81.

19. Babenko F.I., Ivanov V.I., Kovalenko N.A., Rodionov A.K. Temperaturnye ogranicheniia na usloviia transportirovki trub i montazha polietilenovykh truboprovodov [Temperature limits on the conditions of transport of pipes and installation of polyethylene pipes]. Trudy I Evraziiskogo simpoziuma "EURASTRENCOLD-2002" (chast' IV). Iakutskii nauchnyi tsentr Rossiiskoi akademii nauk, 2002, pp. 3-9.

20. Riabets Iu.S., Bulmanis V.N. Prochnost' i deformativnost' polimernykh trub pri ekspluatatsii $\mathrm{v}$ usloviiakh kholodnogo klimata [Strength and deformation of plastic pipes for operation in cold climates]. Izvestiia Sibirskogo otdeleniya Akademii nauk SSSR. Seriya tekhnicheskikh nauk, 1989, vol. 1, pp. 106-109.

21. Struchkov A.S. Khladostoikost' i osobennosti soprotivleniia razrusheniiu neftegazovykh plastmassovykh trub [Cold resistance and fracture resistance characteristics of oil and gas plastic pipe]. Thesis of doctor's degree dissertation. Iakutsk, 2005, 398 p.

22. Anoshkin A.N., Pospelov A.B. Otsenka prochnosti kompozitnykh biplastmassovykh trub pri ikh ekspluatatsii v usloviiakh nizkikh temperatur. [Estimation of durability of composite biplastic pipes at their operation in conditions of low temperatures]. Neftianoe khoziaistvo, 2008, no. 9, pp. 56-58.

23. Bokshitskii M.N. Dlitel'naya prochnost' polimerov [Long-term strength of polymers]. Moscow: Khimiya, 1978. 308 p.

24. Gol'dman A.Ia. Prognozirovanie deformatsionno-prochnostnykh svoistv polimernykh i kompozitsionnykh materialov [Prediction of thermomechanical properties of polymeric and composite materials]. Leningrad: Khimiya, 1988. 272p.

25. Kliueva V.V. Ispytatel'naia tekhnika [Testing Equipment: Handbook. Part 2]. Moscow: Mahinostroenie, 1982. 560 p.

26. Chizhevskii K.G. Raschet kruglykh i kol'tsevykh plastin. Spravochnoe posobie [Calculation of circular and ring plates. Handbook]. Leningrad: Mashinostroenie, 1977. $184 \mathrm{p}$.

27. Anoshkin A.N., Tashkinov A.A., Larionov A.F., Pospelov A.B. Raschet tekhnologicheskikh napriazhenii $\mathrm{v}$ protsesse proizvodstva biplastmassovykh trub [Calculation of stresses in the technological process of production of biplastic pipes]. Moscow: Mashinostroenie, 1997, no. 3, pp. 24-32. 
28. Anoshkin A.N., Larionov A.F., Pospelov A.B., Iakushev R.M. Issledovanie mekhanicheskikh svoistv i otsenka napriazhennogo sostoianiia polietilenovogo sloia biplastmassovykh trub pri nizkikh temperaturakh [Investigation of Mechanical Properties and evaluation of the stress state of the polyethylene layer biplastic pipes at low temperatures]. Vestnik Permskogo gosudarstvennogo tekhnicheskogo universiteta. Aerokosmicheskaia tekhni$k a, 2004$, no. 16 , pp. 5-11.

\section{Об авторах}

Аношкин Александр Николаевич (Пермь, Россия) - доктор технических наук, профессор, начальник Управления науки и инноваций Пермского национального исследовательского политехнического университета (614990, г. Пермь, Комсомольский пр., 29, e-mail: anoshkin@pstu.ru).

Поспелов Алексей Борисович (Пермь, Россия) - главный специалист Научно-образовательного центра авиационных композитных технологий Пермского национального исследовательского политехнического университета (614990, г. Пермь, ул. Академика Королева, 15, e-mail: pospelov-kt@pstu.ru).

Якушев Равиль Максумзянович (Пермь, Россия) - кандидат технических наук, заведующий лабораторией Института технической химии УрО РАН (614013, г. Пермь, ул. Академика Королева, 3, e-mail: ravilyakushev@yandex.ru).

\section{About the authors}

Aleksandr N. Anoshkin (Perm, Russian Federation) - Doctor of Technical Sciences, Professor, Head of Science and Innovation, Perm National Research Polytechnic University (29, Komsomolsky av., 614990, Perm, Russian Federation, e-mail: anoshkin@pstu.ru).

Aleksei B. Pospelov (Perm, Russian Federation) - Chief specialist Scientific and educational center of Aircraft Composite Technology, Perm National Research Polytechnic University (15, Akademik Korolev str., 614990, Perm, Russian Federation, e-mail: pospelov-kt@pstu.ru). 
Ravil' M. Iakushev (Perm, Russian Federation) - Ph.D. in Technical Sciences, Head of Laboratory, Institute of Technical Chemistry, Ural Branch of Russian Academy of Sciences (3, Akademik Koroleva str., 614013, Perm, Russian Federation, e-mail: ravilyakushev@yandex.ru).

Получено 04.03.2014

Просьба ссылаться на эту статью в русскоязычных источниках следующим образом:

Аношкин А.Н., Поспелов А.Б., Якушев Р.М. Особенности деформирования и разрушения комбинированных полимерных труб при низких температурах // Вестник Пермского национального исследовательского политехнического университета. Механика. - 2014. - № 2. - С. 5-28.

Please cite this article in English as:

Anoshkin A.N., Pospelov A.B., Iakushev R.M. Features of low-temperature deformation and fracture of combined plastic pipes. PNRPU Mechanics Bulletin. 2014. No. 2. P. 5-28. 